\title{
PERCEPTION OF ALTERED SMILE ESTHETIC AMONG DENTISTS, STUDENTS AND LAYPERSONS USING DIGITAL PHOTOGRAPHS: A COMPARATIVE STUDY
}

\author{
Erum Amin, Mehwish Khan, Mohammad Omer Siddiqui, Adnan Babar, Fatima Hassan, Wajeeha Ejaz \\ Armed Forces Institute of Dentistry/National University of Medical Sciences (NUMS) Rawalpindi Pakistan
}

\begin{abstract}
Objective: To investigate whether there is any difference in the perception of altered smile esthetics among dentist, students and layperson.

Study Design: Comparative cross sectional study.

Place and Duration of Study: Armed Forces Institutes of Dentistry Rawalpindi, from Jan to Jun 2019.

Methodology: A total of 120 individuals were selected among which 40 were dentists, 40 were students and 40 lay persons to evaluate smile on given questioner. An individual was photographed in frontal posed smile using a digital camera at natural head position. The photograph was digitally manipulated with minor changes and only desired area of face was framed using Adobe Photoshop CC 2018 software to generate a control and ideal smile. Series of photographs were generated by doing modifications to evaluate five variables including Smile arc, Gingival display, Buccal corridor, Midline shift and Midline diastema. The each group was also asked to rate attractiveness each picture on 5 points Visual Analog Scale (VAS) from 1Most attractive to 5- Least attractive.

Results: The $p$-value was for midline diastema and midline shift was $<0.01$. Most of the study population was females 75 $(62.5 \%)$ and the mean age of participants was $27.51 \pm 5.42$. Significant difference was observed at VAS in flat smile arc, nil buccal corridor, mid-line shift and midline diastema by study groups.

Conclusion: Perception of midline diastema and midline shift differs significantly among dentists, students and lay persons.
\end{abstract}

Keywords: Buccal corridors, Esthetic, Perception, Smile.

\footnotetext{
This is an Open Access article distributed under the terms of the Creative Commons Attribution License (https://creativecommons.org/licenses/by-nc/4.0/), which permits unrestricted use, distribution, and reproduction in any medium, provided the original work is properly cited.
}

\section{INTRODUCTION}

Facial attractiveness has been considered as a desirable physical characteristic among all societies for many centuries ${ }^{1,2}$. Facial and dental esthetics becomes the most desirable and increasingly important aspect of orthodontic therapy during the last decade. A well balanced attractive smile is a cherished personal strength and is chief treatment goal of current orthodontic treatment. An individual smile is characterized by the dynamic and static relationship between the dentition and supporting soft tissue framework of face ${ }^{3}$. Various basic components of a balanced smile are facial and dental mid-line relationship, upper lip line and curvature, buccal corridor, smile arc, gingival display, diastema, amount of incisor display at rest and smiling, tooth proportions and cant of occlusal plane ${ }^{4}$. Smiles are classified into two broad categories: Social smile is a voluntary unstrained smile with the static facial expressions and enjoyment smile is an involuntary smile driven by emotions ${ }^{5}$.

The field of orthodontics recently has experienced a "paradigm shift" 6 to focus more on esthetics, with specific emphasis on soft tissues around the mouth.

Correspondence: Dr Adnan Babar, Classified Specialist, Department of Oral \& Maxillofacial Surgery, AFIC Rawalpindi Pakistan

Received: 21 Jun 2020; revised received: 17 Aug 2020; accepted: 26 Aug 2020
Smile analysis is an essential part of the overall facial analysis carried out by orthodontist. An esthetically pleasing smile is dependent on the harmony and symmetry between certain variables ${ }^{3}$, thus comprehensive knowledge of smile components is essential to satisfy patients esthetic demands ${ }^{7}$.

The establishment of esthetics is the initial step towards a pleasant smile that orthodontic patients anticipate from treatment. The orthodontic treatment planning involve the clear understanding of the threshold of what a community consider acceptable in terms of abnormal smile features ${ }^{8}$, patients seeking orthodontic treatment wish to improve their esthetical and social acceptance more than oral function and occlusion.

The perception of smile esthetics is subjective and is influenced by personal experiences, social environment, education, gender, age and culture ${ }^{9}$, for the same reason there is preference difference among layman and professionals regarding smile aesthetics. This fact is concluded in a study which showed difference in smile evaluation among general practitioners, orthodontist and laypersons in Arabic population².

Upper gingival display of $1 \mathrm{~mm}$ was considered as attractive while a distance of $3 \mathrm{~mm}$ is rated as unattractive by both layperson and orthodontists ${ }^{6}$. Large midline diastema was rated as negative influence on 
smile esthetics while a midline diastema of $1.5 \mathrm{~mm}$ was found attractive ${ }^{2}$. Altered photographic framings can be used in smile analysis as an attempt to create harmony between smiles and facial structures ${ }^{10}$.

The objective of study was to investigate whether there is any difference in the perception of altered smile esthetics among dentist, students and layperson.

\section{METHODOLOGY}

This study was conducted at department of orthodontics Armed Forces Institutes of Dentistry Rawalpindi Pakistan, after approval from Research Ethics Committee (Ltr \# 905/Trg - ABP1K2). The duration of study was January to June 2019. Sampling technique was kept non-probability convenience and sample size was calculated by using WHO calculator, Al-Taki et al ${ }^{2}$ study was used with population prevalence proportion of $90 \%$ yielding sample size of more than 100 patients. The formula used as $n=z 2 p(1-p) / d 2, z=95 \%, d=5.5 \%$ and $p=80 \%$. To develop this study, an individual was selected according to following criteria: (1) Have attractive smile closure to text book norms, (2) Age between 20-30 years and (3) Gave consent to volunteer for study. The individual was then photographed at natural head position in a frontal pose smile using a digital camera (Canon EOS-REBEL). The photograph was digitally manipulated using Adobe Photoshop CC 2018 software so that only desired area of face would be framed (fig-1). Only smile was shown in the photographs omitting all the other facial features to reduce any confounding errors. A series of photographs were generated with mild modifications in the smile variables. These modifications from control smile were purposely created to resemble smile esthetic variations and total of 15 photographs were used in this study. The 120 evaluators were selected randomly, including 40 dentists, 40 students and 40 laypersons. The dentists who participated in the study should have at least 2 years of experience. Students were of Final year BDS, with dentistry were excluded. Five different variables including i. Smile arc, ii. Buccal corridor, iii. Mid-line shift, iv. Mid-line diastema and v, Gingival display, were evaluated by the participants. A questioner was generated containing age, gender and occupation of the participants on the front page. Each smile variable pictures were grouped on single page but the sequence was randomized and all measurements of modification were removed and only the pictures were shown to participants. The attractiveness of the smile in each of the modified images was assessed by the three groups and scored using a 5-point VAS with " 1 " indicating the most attractive smile and " 5 " indicating the least attractive smile. Data was analyzed statistically using SPSS 22. The Mean VAS scores and standard deviation (SD) of each group were calculated. Chi-Square test was conducted withineach group to assess how the groups rated each level of deviation. One way ANOVA test was done to compare the means within the group to assess how the groups evaluated each degree of deviation. Post hoc multiple comparisons were made using Bonferroni method to test intragroup significancelevel between two closely related participants.

\section{RESULTS}

A total of 120 individuals participated in the study. The mean age of participants was $27.51 \pm 5.42$ years, mean age of dentists group was $29.65 \pm 4.073$ years, while the mean ages of students and layman groups were $22.70 \pm 0.823$ years and $30.18 \pm 5.764$ years respectively. Out of 120 participants $45(37.5 \%)$ were males and 75 (62.5\%) were females.

In this study results for midline diastema and midline shift were significant $p$-value $<0.01$, showing these smile variables vary significantly among dentists, students and lay persons. On the other hand $p$-value for buccal corridor, gingival display and smile arc were insignificant which identify that changes in these smile variables do not affect the three groups (table-I).

Table-I: Comparison of mean esthetic scores of different smile variables as evaluated by ANOVA in the study populations $(n=120)$.

\begin{tabular}{l|c|c|c|c}
\hline Smile Variables & $\begin{array}{c}\text { Dentist } \mathbf{( n = 4 0 )} \\
\text { Mean } \pm \text { SD }\end{array}$ & $\begin{array}{c}\text { Student } \mathbf{( n = 4 0 )} \\
\text { Mean } \pm \text { SD }\end{array}$ & $\begin{array}{c}\text { Layperson } \mathbf{( n = 4 0 )} \\
\text { Mean } \pm \text { SD }\end{array}$ & $p$-value \\
\hline Midline Diastema & $1.18 \pm 0.385$ & $1.25 \pm 0.439$ & $2.08 \pm 0.730$ & $<0.01$ \\
\hline Buccal Corridor & $1.83 \pm 0.844$ & $1.55 \pm 0.677$ & $1.8 \pm 0.822$ & 0.141 \\
\hline Gingival Display & $1.80 \pm 0.723$ & $1.93 \pm 0.829$ & $1.88 \pm 0.883$ & 0.788 \\
\hline Midline Shift & $1.45 \pm 0.503$ & $1.825 \pm 0.635$ & $2.825 \pm 0.384$ & $<0.01$ \\
\hline Smile Arc & $2.50 \pm 0.679$ & $2.43 \pm 0.747$ & $2.15 \pm 0.834$ & 0.097 \\
\hline
\end{tabular}

while layman were educated and selected on the basis of availability. Layman having if have any affiliation
The fig-2 demonstrates the percentages of studied variable preferred by the different groups of partici- 
pants. As shown in fig- 1 shows that $40 \%$ participants selected $1 \mathrm{~mm}$ while $(31.7 \%)$ people choose $2 \mathrm{~mm}$ midline shift showing significant difference in opinions for

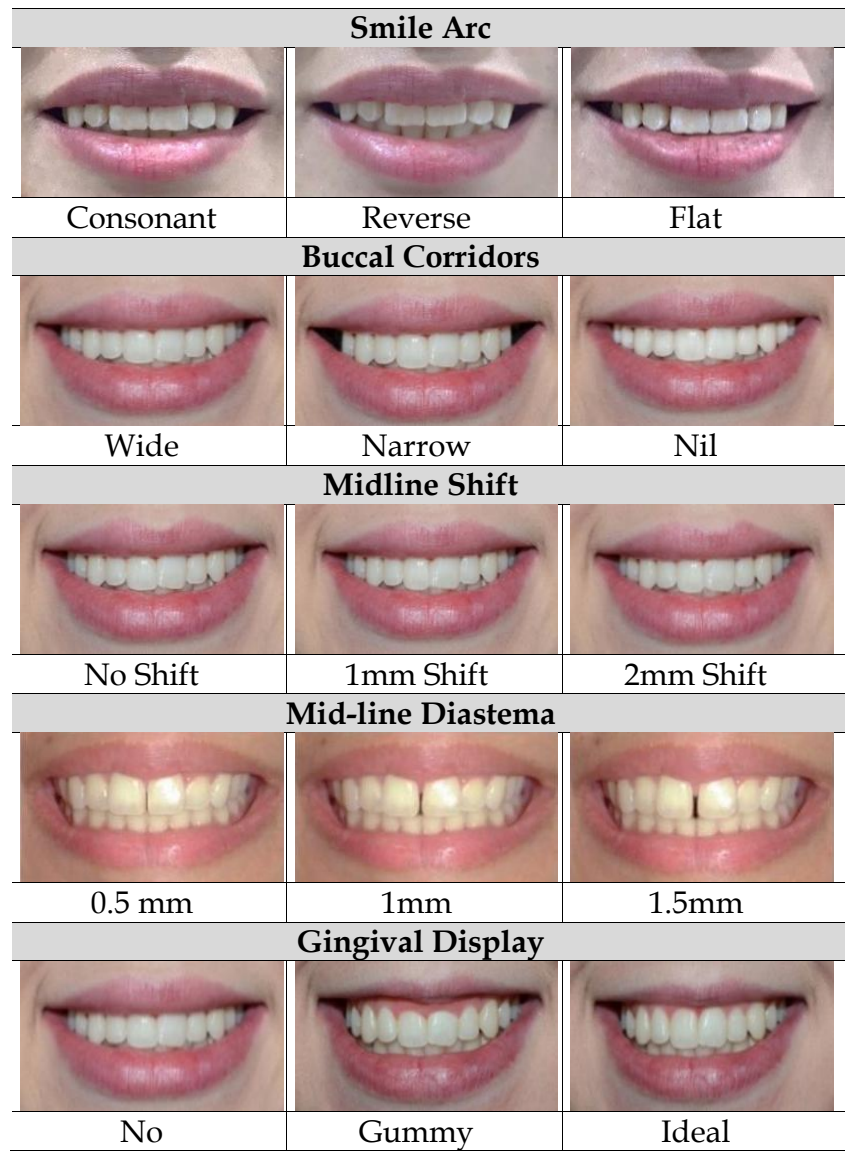

Figure-1: Illustrations of alteration in smile.

midline shift ( $p$-value $<0.01$ ). Multiple comparisons by Boneferroni method concluded a significant difference in smile perception between dentist and layperson and student and layperson ( $p$-value $<0.01)$ (table-II).

The fig- 2 demonstrated that $60 \%$ participants selected $0.5 \mathrm{~mm}$ while $(30 \%)$ people choose $1 \mathrm{~mm}$ midline diastema. The $p$-value was $<0.05(p$-value $<0.01)$

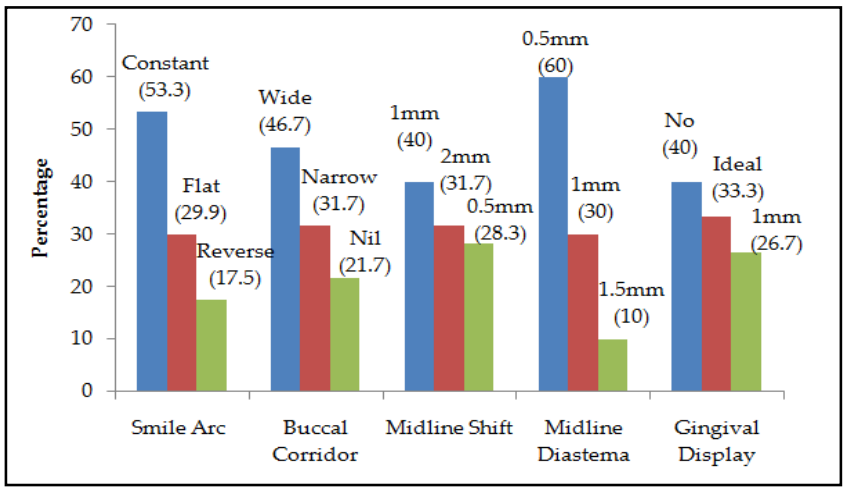

Figure-2: Smile variable preference by study population. for midline diastema and it reveals significant results. Multiple comparisons by Boneferroni method concluded a significant difference in smile perception between dentist and layperson and students and layperson $(p$-value $<0.01)$ (table-II).

Table-II: Intragroup comparison of esthetic scores by Boneferroni's method.

\begin{tabular}{|c|c|c|c|}
\hline $\begin{array}{l}\text { Smile } \\
\text { Variables }\end{array}$ & \multicolumn{2}{|c|}{ Group Comparison } & $\begin{array}{l}\text { Boneferroni } \\
\text { Method }\end{array}$ \\
\hline \multirow{3}{*}{$\begin{array}{l}\text { Mid-line } \\
\text { Diastema }\end{array}$} & Dentist & $\begin{array}{c}\text { Dentist X } \\
\text { Students } \\
\text { Dentist X } \\
\text { Layperson }\end{array}$ & $\begin{array}{l}1.000 \\
<0.01 \\
\end{array}$ \\
\hline & Students & $\begin{array}{l}\text { Students X } \\
\text { Dentist } \\
\text { Students X } \\
\text { Layperson }\end{array}$ & $\begin{array}{l}1.000 \\
<0.01\end{array}$ \\
\hline & Layperson & $\begin{array}{l}\text { Layperson } \\
\text { X Dentist } \\
\text { Layperson } \\
\text { X Students }\end{array}$ & $\begin{array}{l}<0.01 \\
<0.01\end{array}$ \\
\hline \multirow{3}{*}{$\begin{array}{l}\text { Mid-line } \\
\text { Shift }\end{array}$} & Dentist & $\begin{array}{c}\text { Dentist X } \\
\text { Students } \\
\text { Dentist X } \\
\text { Layperson }\end{array}$ & $\begin{array}{l}0.005 \\
<0.01 \\
\end{array}$ \\
\hline & Students & $\begin{array}{l}\text { Students X } \\
\text { Dentist } \\
\text { Students X } \\
\text { Layperson }\end{array}$ & $\begin{array}{l}0.005 \\
<0.01\end{array}$ \\
\hline & Layperson & $\begin{array}{l}\text { Layperson } \\
\text { X Dentist } \\
\text { Layperson } \\
\text { X Students }\end{array}$ & $\begin{array}{l}<0.01 \\
<0.01\end{array}$ \\
\hline
\end{tabular}

Table-III reveals the Means scores and SD and significant findings of perceived attractiveness of the smile in each of the modified images assessed by the three groups scored on a 5-point VAS.

\section{DISCUSSION}

While planning treatment and evaluating its outcome orthodontists must keep in mind the view and perception of society regarding esthetically ideal smile. The perception of society is influenced by multiple factors like education level, ethnicity, age and gender proportions of society ${ }^{11}$. In this study dentists, students and lay persons evaluated the beauty of smile on the basis of five variables, that were; smile arc, midline diastemas, buccal corridor, gingival display and midline shift.

The results of Zabba ${ }^{12}$ and Springer ${ }^{13}$ studies concluded that, the distance of $2 \mathrm{~mm}$ between smile arc and lower lip is ideal. Increased curvature or reverse 
curvature and flattening of smile arc has negative impact on layman perception ${ }^{14}$. Some previous studies from Parekh ${ }^{15}$ and $\mathrm{Ker}^{16}$ established that flatter smile arcs are more objectionable while more upward curvature than that follows the lower lip was graded unpleasant. These results are in harmony with the results of our study in which consonant smile $(53.3 \%)$ is preferred by the most individuals as compared to the reverse or flat smile arc, however no significant difference was observed in the perception of smile arc among dentists, students and layman.

Table-III: Comparison of esthetic scores on visual analog scale.

\begin{tabular}{l|c|c}
\hline Variable & $\begin{array}{c}\text { Visual Analog Scale } \\
\text { Means } \pm \text { SD }\end{array}$ & $p$-value \\
\hline Smile Arc & $2.56 \pm 1.172$ & 0.217 \\
\hline Consonant & $3.73 \pm 1.282$ & 0.040 \\
\hline Reverse & $3.41 \pm 1.393$ & 0.283 \\
\hline Flat & $2.08 \pm 1.089$ & 0.895 \\
\hline Buccal Corridors & $3.23 \pm 1.242$ & 0.391 \\
\hline Wide & $3.21 \pm 1.408$ & 0.032 \\
\hline Narrow & $3.26 \pm 1.404$ & $<0.01$ \\
\hline Nil & $2.89 \pm 1.448$ & 0.004 \\
\hline Mid-line Diastema & $4.13 \pm 1.202$ & $<0.01$ \\
\hline 0.5mm & $1.93 \pm 1.067$ & $<0.01$ \\
\hline 1mm & $3.36 \pm 1.075$ & $<0.01$ \\
\hline 1.5mm & $3.85 \pm 1.171$ & $<0.01$ \\
\hline Mid-line Shift & $3.27 \pm 1.510$ & 0.503 \\
\hline No shift & $3.52 \pm 1.432$ & 0.088 \\
\hline 1mm Shift & $2.81 \pm 1.259$ & 0.211 \\
\hline Lmm Shift
\end{tabular}

A study conducted by Gaikwad et al17 revealed that orthodontists were more specific in perceiving the smile arc and buccal corridor as compared to the dentists and layperson. Similar results were obtained in the study conducted by Kiania et al ${ }^{18}$ for the evaluation of buccal corridor among orthodontists and lay persons. Smaller buccal corridors are preferred by both orthodontists and lay persons as compared to broader corridors. A study conducted by Taki et al ${ }^{2}$ revealed that there is a significant difference in the perception of smile esthetics and buccal corridor among orthodontists, dentists and lay persons. These results are inconsistent to this study. This difference in results can be attributed to cultural, ethnical and racial differences.

Midline shift of more than $2.0 \mathrm{~mm}$ is noticeable by the lay persons, 7 while some other studies suggested midline shift as much as $4.0 \mathrm{~mm}$ is acceptable by the lay persons ${ }^{11}$. In this study majority of the participants (40\%) preferred $1 \mathrm{~mm}$ midline shift as esthetically preferred smile. A study conducted by Omar ${ }^{19}$ revealed that dental students are more precise in picking up midline shift discrepancies than non-dental students. While this study concluded that there is a significant difference in perception of esthetically preferred smile among the three groups with respect to midline shift. Intra-group comparison of esthetic scores (table-II) shows significant difference between students and layperson and dentist and layperson.

Midline diastema of $>1 \mathrm{~mm}$ is find unattractive by orthodontists while general practitioners and lay persons find midline diastema of $2 \mathrm{~mm}$ or more unattractive $^{20}$. Another study ${ }^{21}$ concluded that lay dentists and laypersons found midline diastema of $1 \mathrm{~mm}$ unattractive $^{26}$. Increasing midline diastema is regarded as an unattractive feature in this study as majority $(60 \%)$ of participants preferred the smile with $0.5 \mathrm{~mm}$ of midline diastema. Ours study also found that there is a significant difference between dentists and layperson and students and layperson in perception of midline diastema.

Orthodontists, dentists and lay persons graded gingival display of $2 \mathrm{~mm}$ or more un attractive ${ }^{2}$. How Hoe et a ${ }^{22}$ concluded that $1 \mathrm{~mm}$ or more of gingival display is unattractive while Kokich ${ }^{23}$ and $\mathrm{An}^{24}$ et al concluded that gingival display of $4 \mathrm{~mm}$ or more is appreciable by general practitioners and lay persons. In this study majority $(48 \%)$ of the participants preferred no gingival display, while about equal proportions (33.3\%) preferred gummy and ideal smiles. Our study also revealed that there is significant difference in perception of gingival display as esthetic smile variable among dentists and laypersons and also among study population. As the concept of beauty is personal, hence subjective, it requires a fast, straight forward and reliable evaluation method. Therefore, VAS was used as research tool in this study. A significant difference in smile perception was observed in scores of midline diastema and midline shift on VAS (table-III), the study based on Korean and Japanese ${ }^{25}$ orthodontist showed that was the median esthetic score of standard composite smile in the Korean orthodontist was clinically significantly lower than that of the Japanese orthodontist. In our study means score of midline line diastema was higher as compared to other variables.

The limitations of our study are that all the photographs use were of female smiles and socioeconomic 
and education level of laypersons were not considered while selecting laypersons.

\section{CONCLUSION}

Dentists were more analytical in smile perception as compared to students and layperson. Perception of midline diastema differs significantly in between dentist and layperson and students and layperson while perception of midline shift differs significantly between dentist and layperson and student and layperson. The more importance should be given to the esthetics demands of patients before planning any orthodontics treatment.

\section{CONFLICT OF INTREST}

The study has no conflict of interest to be declared by any author.

\section{REFERENCES}

1. Naqvi ZA, Shaikh S, Pasha Z. Perception of facial profile and orthodontic treatment outcome-importance of patient's opinion in treatment plan. Int Dent Med J Adv Res 2015; 1(1): 1-5.

2. Al Taki A, Khalesi M, Shagmani M, Yahia I. Perception of altered smile esthetics: A comparative evaluation in orthodontists, dentist and layperson. Int J Dent 2016; 46(2): 227-39.

3. Profit WR, Fields HW, Larson B, Sarver DM. Contemporary orthodontics. 6th ed. St. Louis: Mosbay; 2018.

4. Kallidass P, Srinivas S, Charles A, Davis D, Charravarthi NS. Smile characteristics in orthodontics: A concept review. Int J Orofac Res 2017; 2(1): 1-4.

5. Munjal P, Chhabra S. Smile and its components-A review. Int J Appl Dent Sci 2017; 3(3): 167-70.

6. Memon W, Ghani A, Naz I, Jatoi NH, Ali A. Smile perception among orthodontist and layperson. Pak Orth J 2017; 9(1): 56-60.

7. Ferreira JB, Silva LE, Caetano MTO, Motta AFJ, Saramago AAC, Mucha JN. Perception of midline deviation in smile esthetics by laypersons. Dent Press J Orthod 2016; 21(6): 51-57.

8. Hussain S, Joshi V, Arora S, Ali N. Facial aesthetics- Review. Int J Curr Res 2015; 7(4): 17577-82.

9. Fernandes L, Pinho T. Esthetic evaluation of dental and gingival asymmetries. Int Orthodont 2015; 13(2): 221-31.

10. Rosa M, Olimpo A, Fastuca R, Caprioglio A. Perceptions of dental professionals and laypeople to altered dental esthetics in cases with congenitally missing maxillary lateral incisors. Prog Orthod 2013; 14(1): 34 .
11. Narmada S, Senthil Kumar K, Raja S. Management of mid-line discrepencies: A review. J Indian Acad Dent Spec Res 2015; 2(2): 45-48.

12. Zaaba NA, Pandian S. Influence of lip height and inciso gingival height in relation to smile aesthetics in orthodontically treated individuals. Research J Pharm Tech 2018; 11(12): 5581-86.

13. Springer NC, Chang C, Fields HW, Beck FM, Firestone AR, Rosenstiel S, et al. Smile esthetics from the layperson's perspective. Am J Orthod Dentofacial Orthop 2011; 139(1): e91-101.

14. Parrini S. Laypeople's perceptions of frontal smile esthetics: A systematic review. Am J Orthod Dentofacial Orthop 2016; 150(5): 740-50.

15. Parekh S, Fields HW, Beck FM, Rosenstiel SF. The acceptability of variations in smile arc and buccal corridor space. Orthod Craniofac Res 2007; 10(1): 15-21.

16. Ker AJ, Chan R, Fields HW, Beck M, Rosenstiel S. Esthetics and smile characteristics from the layperson's perspective: a computer-based survey study. J Am Dent Assoc 2008; 139(10): 1318-27.

17. Gaikwad S, Kaur H, Vaz AC, Singh B, Tane L, Vinod KS, et al. Influence of smile arc and buccal corridors on facial attractiveness: a cross-sectional study. J Clin Diagn Res 2016; 10(9): 20-23.

18. Kiani H, Bahir U, Durrani OK, Zulfiqar K. Comparison of difference in perception between orthodontists and laypersons in terms of variations in buccal corridor space using visual analogue scale. Pak Oral Dental J 2013; 5(2): 67-72.

19. Omar H, Tai YT. Perception of smile esthetics among dental and nondental students. J Educ Ethics Dent 2014; 4(2): 54-60.

20. Bolanle Akinboboye BD. Transcultural perception of maxillary midline diastema. Int J Esthet Dent 2015; 10: 610-17.

21. Mokhtar HA, Abuljadayel LW, Al-Ali RM, Yousef M. The perception of smile attractiveness among Saudi population. Clin Cosmet Investig Dent 2015; 7: 17-23.

22. Hoe TM, Ting J, Chui LS, Wen TM, Al-Juboori MJ. Variables and factors that may affect smile design: A mini review. Int J Contemp Dent Med Rev 2015; 1: 1-4.

23. Kokich VO, Kokich VG, Kiyak HA. Perceptions of dental professionals and laypersons to altered dental esthetics: asymmetric and symmetric situations. Am J Orthod Dentofacial Orthop 2006; 130(2): 141-51.

24. An SM, Choi SY, Chung YW, Jang TH, Kang KH. Comparing esthetic smile perceptions among laypersons with and without orthodontic treatment experience and dentists. Korean J Orthod 2014; 44(6): 294-303.

25. Loi H, Kang S, Shimomura T, Kim S, Park S, Son W, Takahashi I. Effects of buccal corridors on smile esthetics in Japanese and Korean orthodontics and orthodontics patients. Am J Orthod Dentofacial Orthop 2012; 142(4): 459-65. 